EDITOR'S NOTE FOR VOLUME 3, MODULE 4: Paul W. Clement has conducted an active private psychotherapy practice since 1966, seeing a total of 1291 clients in completed therapy as of mid July, 2006. Throughout this time, he has employed an innovative, integrative theoretical model which is inspired primarily by cognitive-behavioral, personcentered, and positive psychology concepts, and which is pragmatically rooted in his private practice experience.

What makes Clement's practice particularly distinctive has been his ongoing commitment to developing and implementing methodologies for the systematic, quantitative evaluation of all his clients. Using the "treatment effect size" (ES) statistic (e.g., Smith \& Glass, 1977), Clement has shown how individual practitioners can be accountable within the context of research-based benchmarks of outcome in the field, thus providing a crucial bridge in psychotherapy between traditional practice, on the one hand, and effectivenessbased and efficacy-based group research studies, on the other.

With the above in mind, I am pleased to have in PCSP a systematic case study -- the Story of "Hope" -- from Clement's practice, in honor of his 40-year clinical career. In line with the goals of PCSP, notable aspects of his case study are: (a) the inclusion of a detailed description of the development and application of his distinctive theoretical model; (b) the inclusion of rich, concrete details to describe the process of his therapy with the case of Hope; and (c) an illustration of the process of integrating quantitative norms from within his practice to inform the qualitative description and analysis of one of his individual cases. These three aspects of his case study reflect the larger issues involved in how to bring together the research and the clinical dimensions of psychotherapy within the naturalistic setting of a 40-year private practice.

I am also very happy that Clement's important clinical work is being commented upon by two of today's leading figures in psychotherapy research, accountability, and policy development: Alan E. Kazdin, from Yale University and the current President-Elect of the American Psychological Association (APA); and David H. Barlow, from Boston University and a recent member of the APA Presidential Task Force (2006) on "Evidence-Based Practice in Psychology."

\title{
Story of "Hope": \\ Successful Treatment of Obsessive Compulsive Disorder
}

\section{PAUL W. CLEMENT ${ }^{\mathrm{a}, \mathrm{b}}$}

${ }^{\text {a }}$ Private practice, South Pasadena, CA

b Correspondence concerning this article should be addressed to Paul W. Clement, 719 Fremont Avenue, South Pasadena, CA 91030.

Email: PaulWClement@aol.com

\begin{abstract}
The client Hope provides a good example of a very positive outcome from sustained, multifaceted psychotherapy with a 30-year-old woman presenting with obsessive compulsive disorder (OCD), fear of flying, panic disorder without agoraphobia, nightmare disorder, and a childhood history of separation anxiety disorder. Based on ratings at the beginning of therapy and end of therapy on a structured, self-report instrument, and relative to other, similar clients in my practice and as reported in research studies, Hope achieved a very successful result after 103
\end{abstract}


sessions of psychotherapy during a period of about two and a half years, and she maintained her gains during one-year follow-up. Specifically, Hope achieved a treatment effect size (ES) of 3.95 at termination and of 3.81 at one-year follow-up, compared with a mean ES of 1.65 at termination for OCD clients in my practice, and compared with mean ESs ranging from 1.12 to 1.56 as reported in meta-analyses of OCD clients in randomized clinical trials. This case study report presents both a systematic, qualitative description of the case together with an illustration of how an individual case in a private practice can be quantitatively compared with other, similar cases seen by the same therapist and with similar, research cases reported in the literature. The case study is intended to illustrate an integration of two sets of recommendations about therapy practice that I endorse from the American Psychological Association's Clinical Psychology and Psychotherapy Divisions, namely, recommendations for the use of empirically supported treatments and for the use of empirically supported therapy relationships, respectively.

Key words: pragmatic psychotherapy; obsessive compulsive disorder; flying phobia; separation anxiety disorder; treatment effect size; cognitive behavioral therapy; client-centered therapy; common factors in therapy

\section{CASE CONTEXT AND METHOD}

\section{A. The Rationale for Selecting This Particular Client for Study}

Hope first came to see me when she was 30 years old. Although her primary diagnosis was Obsessive Compulsive Disorder (OCD), she met the criteria for several other disorders. She had a life-long history of experiencing excessive anxiety and probably met the criteria for Separation Anxiety Disorder as a child. Two psychiatrists and one psychologist had treated her prior to her coming to see me. In spite of her reporting benefits from this preceding treatment, the OCD was still plaguing her life.

During my past 40 years in private practice, I have developed and maintained a quantitative and qualitative database of the 1291 clients I have seen in completed therapy, in part as a way of providing a quantitative context for understanding and interpreting the presenting characteristics and outcome results for any particular client. This database indicates that over the 40 years, 64 individuals have come to see me for the treatment of OCD, with the following ages:

- 2 were less than 6 years old

- 5 were from 6 to 12 years old

- 9 were from 13 to 18

- 12 were from 19 to 29

- 20 were from 30 to 39

- 12 were from 40 to 49

- 2 were from 50 to 59, and

- 1 was from 60 to 69 .

Thus Hope was the modal age for private patients seen during my career with the OCD diagnosis.

Of the 64 cases, 15 dropped out during the initial three sessions, producing a drop-out rate of $23.4 \%$, and these clients were not included in my analysis of treatment outcomes. One 
Story of "Hope": Successful Treatment of Obsessive Compulsive Disorder

P.W. Clement

Submitted to: Pragmatic Case Studies in Psychotherapy, http://pcsp.libraries.rutgers.edu

Volume 3, Module 4, Article 1, pp. 1-36, 10-01-07 [copyright by author]

additional case was still in treatment and was not included in the following analysis. Of the remaining 48 cases,

- $1(2 \%)$ was "Much Worse" at termination than at intake

- nobody was "Worse,"

- 17 (35\%) showed "No Change”

- 18 (38\%) were "Improved," and

- 12 (25\%) were "Much Improved.”

This yields an over-all improvement rate across treated cases of $63 \%$. Using a scoring system such that much worse than at intake $=1$, worse than at intake $=2$, no change from intake to termination $=3$, improved $=4$, and much improved $=5$, the mean rating for the 48 cases was 3.83. (Note that this was virtually identical to the 3.81 obtained for the 16 cases I had seen after 26 years of private practice [Clement, 1994].) At termination Hope's score was 5 (much improved).

Following the publication of my 1994 article cited in the preceding paragraph, I developed a method for calculating Smith and Glass (1977) and Smith et al.'s (1980) statistic of "treatment effect size" for individual cases as well as across sets of individual cases (Clement, 1996, 1999; the procedure for doing this is described later in the text below and summarized in Table 2). The median of 28 effect sizes from cases of OCD treated in the past 14 years of my private practice is 1.30 and the mean is 1.65 . These results are very similar to those reported by Eddy, Dutra, Bardley, and Westen (2004). They did a meta-analysis of randomized clinical trials (RCTs) that included psychotherapeutic treatments of OCD published between 1980 and 2001. One of their analyses calculated effect sizes within the treated patients by comparing their pretreatment with their post-treatment scores. The mean effect size was $1.52(\mathrm{SD}=0.66)$ and the median was 1.19. Hope's treatment effect size at termination was 3.95, indicating that she had a very positive outcome.

The average number of treatment sessions for the 48 cases discussed above was 31 with a range of 4 to 252. Hope had completed 103 sessions at the time of her termination. Summing across all completed treatment cases $(n=1291)$ during the first 40 years of my private practice, the median number of sessions per case has been 10 and the mean 17, and Hope's treatment duration was actually at the $99^{\text {th }}$ percentile. Thus Hope was one of my longest cases.

I chose Hope for the present case study because she provided a good example of a very positive outcome from sustained, multifaceted psychotherapy with a young adult with multiple diagnoses. In addition to meeting the criteria for OCD, she met those for Specific Phobia (flying), Panic Disorder without Agoraphobia, and Nightmare Disorder. Also, the Separation Anxiety Disorder that was probably present in her as a child had manifestations in her as an adult. These multiple diagnoses are one of the reasons for selecting Hope's story. In naturalistic studies of treatment in the community, comorbidity is the norm rather than the exception (Westen, D., Novotny, C. M., \& Thompson-Brenner, 2004). Another reason for telling Hope’s story was that her treatment was consistent with naturalistic studies of psychotherapy that show a dose-response relationship in which treatments that last one to two years or more produce greater 
improvements than briefer treatments (Howard, Kopta, Krause, \& Orlinsky, 1986; Kopta, Howard, Lowry, \& Beutler, 1994; Seligman, 1995). This has been specifically true with my own clients. For example, in an analysis of all the 683 patients in my first 26 years of practice, there was a correlation of .52 between number of sessions and degree of success at outcome (Clement, 1994).

\section{B. The Methodological Strategies Employed for Enhancing the Rigor of the Study}

This was a routine treatment case. I did not employ any special methodological strategies for this case specifically to enhance the rigor of the study. I did ask Hope to evaluate herself at intake using the Adult Problems Checklist (Clement, 1999; see Appendix 1) and to re-evaluate herself on the same instrument during our $14^{\text {th }}, 69^{\text {th }}$, and last, $103^{\text {rd }}$ session, and at one-year follow-up. Following each of these re-evaluations, I calculated a treatment effect size using the formula that I employ with all the cases in my practice for which I have adequate data (Clement, 1996, 1999). This formula uses the data from how the client was functioning at intake as the point of reference for all subsequent re-evaluations. It applies much of the logic from metaanalysis as introduced by Smith and Glass (1977) and Smith, Glass, and Miller (1980) to outcomes for individuals or sets of individuals. Rather than comparing mean scores of treated and control or contrast groups across multiple studies, as done in typical meta-analyses, my approach makes comparisons across multiple measures within an individual client, with each client serving as his/her own control.

Before applying this approach to my private cases I had looked for a way to quantify the results of single-subject $(N=1)$ studies and to statistically summarize the results from sets of such studies. I had been impressed with experiments published in the Journal of Applied Behavior Analysis during the 1960s and 1970s, but the authors of those articles usually depended on visual analysis of their results. They eschewed the use of statistical analyses. When I read Smith and Glass (1977) and Smith et al. (1980), I decided to adapt their approach to my singlesubject experiments in order to express mathematically how much each subject changed from baseline to each experimental intervention and in order to sum across sets of single-subject experiments. An example of this approach appeared in Clement, Anderson, Arnold, Butman, Fantuzzo, and Low (1982). I did not apply this approach to my private cases until more than a decade later.

In my professional practice, I have found that prospective clients or people at the beginning of therapy do not ask me to tell them about group research and efficacy studies. They want to know what the odds are of their improving if they see me in treatment and how much can they expect to gain. They are interested in personal (i.e., within-client) change; they do not express interest in how they compare to means for groups of treatment or comparison conditions in controlled-treatment, outcome studies. Normally I give my clients a copy of each reevaluation of their progress as their "therapy report card." 


\section{The Clinical Setting in Which the Case Took Place}

All sessions occurred in my private office. It is on the ground floor of a two-story house built in 1890. Eight clinical psychologists practice at this location. The owner is one of the eight. He purchased the house and made very extensive renovations converting the house into office space a few years ago.

\section{Sources of Data Available Concerning the Client}

The client was the sole source of information about her functioning before, during, and following treatment. The assessment instruments that I used included a clinical history; the Adult Self-Report Inventory-4 (ASRI-4; Checkmate Plus, 1999); the Adult Problems Checklist (Clement, 1999; see Appendix 1); clinical interviews; and a quantitative, overall evaluation of progress/outcome during sessions 14, 69, and 103.

As I do with all adults at intake, I asked Hope to fill out the Adult Problems Checklist (Appendix 1) in the waiting room before I began interviewing her. This instrument consists of 69 items plus three blank lines marked “other." The items cover the most common concerns that adults bring to outpatient psychotherapy. This checklist is very helpful in identifying the client's particular problems that they want to address in therapy. In addition, at the beginning of the intake interview I ask the client to tell me in his/her own words the reasons for seeking treatment at this point in time, whether any critical incident made these issues or problems surface, and what results the client expects from treatment. The information obtained from the checklist and the history gathered and direct observations made during the intake interview provide most of the information that I need to formulate my initial diagnostic impressions.

At the end of the first session I give the new adult client a copy of the Adult Self-Report Inventory-4 (ASRI-4) to take home, complete, and then return to me at our second session. The ASRI-4 consists of 135 items that the respondent rates "Never," "Sometimes," "Often," or "Very Often.” In some cases I also give a copy of the Adult Inventory-4 (AI-4) for a spouse or significant other adult to complete, but I did not do so in Hope's case. There are two ways to score the ASRI-4 and the AI-4 instruments: the symptom count method and the symptom severity model. Both approaches are intended to help the clinician identify whether the client meets the criteria for one or more of more than two dozen DSM-IV-TR diagnoses. I score the client's responses on the ASRI-4 between the second and third sessions. I use it primarily as a cross-check of my initial diagnostic impressions. When I get an AI-4 from a significant other, I use it in the same way as a diagnostic cross-check.

\section{E. Confidentiality}

Names, nationality, and other specific identifiers have been changed in the following presentation in order to protect the identity of the client. Prior to my publishing this paper I asked Hope to read it for accuracy and for adequate protection of her identity.

\section{THE CLIENT}

Hope was 30 years old at intake. Her stated reasons for seeking treatment were: "I have always been a perfectionist. I 'tidy up.' If I don’t tidy up, people will die. If I resist tidying up, 
I get so anxious that I can't focus.” Shortly before she called for treatment, her husband had been on a business trip. While he was gone, she had recurring obsessions that tidying up would give protection against anything bad happening to him while he was traveling. In contrast, if she didn’t tidy up, he would probably die or be injured.

\section{GUIDING CONCEPTION WITH SUPPORT FROM RESEARCH AND CLINICAL EXPERIENCE}

Over the years I have developed a general, integrative theoretical model of psychotherapy for working with both children, adolescents, and adults that flows from many branches of psychology. Below I outline some of the basic concepts within this model and where they come from.

\section{“Readiness" for Treatment and "Stages of Change"}

When I began my career, I was intending to work primarily with children, adolescents, parents, teachers, and other adults who work with children. In light of that plan, I was interested in the contributions of developmental psychology. One such item is the concept of "readiness." It has a long history in child psychology, for example, readiness for toilet training or readiness for reading. Similarly, people vary greatly in their readiness for change when they enter psychotherapy. Children rarely ask to see a psychologist. Their entering therapy is someone else's idea. They tend to deny knowing the reason(s) someone wants them in therapy and they have no desire to change. They are in what Prochaska, DiClemente, and Norcross (1992) called the pre-contemplation stage of change: There is no intention to change and no personal recognition that a problem exists.

These authors (Prochaska et al., 1992) identified four additional stages of change. Contemplation is the stage in which personal awareness of the problem exists, the person thinks about overcoming the problem, but there is no commitment to action. Preparation covers the phase in which the person decides to take action toward change within the next month. Action is when the person modifies his/her thoughts, feelings, actions, or environment in order to solve their problems. Maintenance includes when the gains achieved in the action stage are consolidated and strategies to prevent relapse are used. Clearly when Hope first came to see me, she was in the action phase.

\section{Common Factors}

In addition to concepts of readiness and stages of change, there is a very long history of attempts to identify common factors that are present in many approaches to psychotherapy and that are at least partially responsible for producing desired changes. Seventy years ago Saul Rosenzweig (1936) published an article, "Some Implicit Common Factors in Diverse Methods of Psychotherapy.” Rosenzweig did not provide an extensive list of common factors. Rather, he articulated the hypothesis that such variables must exist, such as, social reconditioning, catharsis, the therapist's personality, and the provision of a conceptual scheme for the client to make sense out of their problems and solutions. 
Just over 20 years later Carl Rogers (1957) published his famous paper identifying the necessary and sufficient factors to produce therapeutic change: (1) The two persons (therapist and client) had to have contact. (2) The one seeking help had to be in some kind of distress. (3) The helper had to be congruent (i.e., authentic or genuine). (4) The helper had to experience unconditional positive regard for the client (i.e., acceptance). (5) The helper had to experience an empathic understanding of the one being helped. (6) The helper had to communicate this empathic understanding and acceptance at least to a minimal degree. Rogers asserted that doing these six things would produce positive change. Clearly his list is an example of common factors.

\section{The Challenge of the Eysenck and Levitt Studies}

In contrast to articles such as the two mentioned in the preceding two paragraphs asserting that psychotherapy frequently produces positive changes in people who undergo treatment, Eysenck (1952) reviewed 19 studies of adult psychotherapy outcomes including over 7,000 cases receiving both psychoanalytic and eclectic types of treatment. His conclusion was, "The figures fail to support the hypothesis that psychotherapy facilitates recovery from neurotic disorder" (p. 323). Five years later Levitt (1957) reviewed treatment outcome studies with children and came to a similar conclusion: "It now appears that Eysenck's conclusion concerning the data for adult psychotherapy is applicable to children as well; the results do not support the hypothesis that recovery from neurotic disorder is facilitated by psychotherapy” (p. 193). Six years later Levitt (1963) updated his review and concluded, "[T]here is no sound basis for the hypothesis that psychotherapy facilitates recovery from emotional illness in children” (p. 45). These conclusions of Eysenck and Levitt were very provocative for both psychotherapy researchers and practitioners. Fourteen years after his initial review Eysenck (1966) reviewed outcome studies for both children and adults and came to the same conclusion as he originally did: "When untreated neurotic control groups are compared with experimental groups of neurotic patients treated by means of psychotherapy, both groups recover to approximately the same extent” (p. 39). These reviews by Eysenck and Levitt posed a major challenge for anyone doing psychotherapy or performing research on therapy outcomes as well as to those of us who were still in training to do so.

\section{Parallels Between the Therapist Role and Being a Swimming Instructor or Lifeguard}

Prior to my beginning my study of psychology I had been a swimming instructor and a lifeguard. As a swimming instructor I learned to help frightened children learn how to swim by (a) assessing their level of fear and water safety skills at the beginning of the first lesson, (b) matching the first lesson to their level of confidence and competence, (c) modeling or demonstrating a task that I believed s/he could and would do, (d) asking the child to do that task, (e) having the child repeat the task until s/he was fully relaxed, (f) very gradually increasing the difficulty or challenge of each successive task, and (g) celebrating (i.e., socially reinforcing) each success. Many years later when I read about systematic desensitization (Wolpe, 1961) I was struck by the similarities between what I had learned to do as a swimming instructor and Wolpe's approach. 
My experiences as a lifeguard also informed my later practice of psychotherapy. For three of my 11 consecutive summers of working on the water I was an ocean lifeguard on the northern Oregon coast. I had learned that the best rescue is one that the victim makes for him/herself. The lifeguard swims close to the victim without making physical contact. Then the lifeguard talks to the victim giving reassurance, assesses the victim's ability to respond to directions and to help him/herself, tells the victim what to do, and then swims near the victim as they move toward shore and safety. Similarly, as a psychotherapist I believe that the best treatment is one that the client or patient executes on him/herself.

\section{The Use of Reinforcers}

Donna Gelfand and Donald Hartman supervised a fellow intern and me in our conducting group play therapy with six boys in the 1964-65 training year. Five of the boys were hyperactive, impulsive, and oppositional. One was shy and withdrawn. Following the first several months of treatment the boys' behavior was worse during sessions than it had been at the onset of therapy; so the supervisors recommended that we try some of "that new M\&M therapy." We began to reinforce socially appropriate and cooperative behaviors with candy and social reinforcers, and the boys' behavior showed a stunning improvement. Based on this clinical success (Clement, 1968), I decided to do research on child group therapy during the first several years of my career. My basic approach was to add components (token reinforcers, social reinforcers, videotaped models) to the treatment methods that I had learned during graduate school to see whether those components would improve measured outcomes (Clement \& Milne, 1967; Clement, Fazonne, \& Goldstein, 1970; Clement, Roberts, \& Lantz, 1970).

\section{Self-Regulation and the Development of 39 Treatment Interventions}

In 1969 a foster mother brought a nine-year-old girl to me for treatment in my private practice. For various reasons I implemented a self-regulation plan with her. She was very frequently in trouble in her classroom. Most of her misbehaviors occurred when she was out of her seat; therefore, we chose in-seat behavior as the target. We made an agreement that she would do the following: (a) She would use a five-minute hour-glass-type egg timer to track each five minutes that her bottom stayed in continuous contact with her chair. (b) At the end of each successful interval she would make a check mark on a special sheet that I gave her. (c) Each day she would take that sheet home and telephone my secretary giving the number of check marks for the day. (d) I wrote a brief note to the teacher explaining the intervention.

Although nobody provided back-up reinforcers for the self-administered check marks, after two weeks on this self-regulation program the teacher reported a dramatic change for the better in the girl's behavior. Given the success with this individual case, I launched a research program on self-regulation, self-control, and self-management in children that lasted for about the next 20 years. The process of writing treatment plans for intervention packages that children carried out on themselves called for great clarity and specificity. This need motivated me to develop a system for describing therapeutic interventions (Clement, 1980). The system includes 39 generic interventions. The therapist, the child, or both of them working in concert may apply one or more of these interventions thereby making possible the creation of thousands of unique combinations or distinctive treatment packages. The 39 interventions fall under four broader 
categories: (a) setting events, (b) cues and prods, (c) primary behaviors, and (d) consequences and feedback.

Setting events are variables that affect the general state of the individual, thereby changing thresholds for (1) cues, prods (conditional or unconditional stimuli), or social models; or for (2) conditional or unconditional reflexes; or for (3) positive or negative reinforcers; or (4) changing the spontaneous rates of actions. Examples of biological setting events include hormones, psychoactive drugs, and body temperature. Examples of genetic setting events are individual differences such as temperament (e.g., shyness or impulsiveness). Examples of shortterm experiential setting events are rest — fatigue or satiation — deprivation of food or water or the frequency, recentness, duration, or amount of reinforcement/punishment. An example of social setting events is acceptance or rejection by others. Examples of cognitive setting events include values, attitudes, beliefs, or the therapist's providing a rationale for a particular treatment. An example of perceptual setting events is one's perceived distance from a goal. Finally, examples of setting events that occur at the onset of any social encounter are one's answers to the following questions: Is this about me or is this about you? Is this your territory or is this my territory? Is this going to be friendly or is this going to be unfriendly? Each question is asked and answered in a flash, and the answers have a big impact on subsequent behavior.

Cues refer to signals for particular actions. Prods refer to conditional and unconditional stimuli that trigger emotions or other reflexes. One type of cue includes live, filmed, and symbolic social models. Genuineness or authenticity in the therapist seems to facilitate therapeutic change via mechanisms of modeling. Emotions constitute an important set of internal cues: for example, anger, anxiety, compassion, disgust, envy, fright, gratitude, guilt, happiness, hope, jealousy, love, pride, relief, sadness, and shame. Requests, suggestions, directions, homework assignments, and coaching from the therapist are examples of external cues. Goals and a wide range of cognitions that have the form of self-administered directions are examples of internal cues. External stimuli that trigger fear and avoidance in persons with phobias are one example of prods. The cognitions that constitute worry or obsessing are examples of internal events that trigger anxiety and avoidance, escape, or rituals.

Primary behaviors consist of actions or reflexes. Actions are behaviors that are influenced primarily by their consequences. Reflexes are behaviors that are triggered by their antecedents. In most arenas of life a powerful tool for fostering learning and behavioral change has been practice of desired actions. Practice is a standard part of education (e.g., class work and homework), sports/athletics, music (vocal and instrumental), public speaking and debate, and virtually all other areas of skilled performance. In the psychotherapeutic literature practice has been identified in various ways including role playing, behavioral rehearsal, positive practice, over correction, and therapeutic homework. Therapists seem to have placed much less emphasis on dealing directly with reflexes than with actions. To a great extent cognitions seem to function as covert actions.

Consequences and feedback refer to what normally follows actions or thoughts. Within the process of psychotherapy empathic responses, interpretations, and verbalized observations are common forms of social consequences and feedback. Over the decades I have often explained during therapy that virtually all socialized people spend time every day in front of a 
glass mirror. A glass mirror does not do anything to the person; rather, it does something for the person. It lets the user see how s/he looks on the outside by providing a reflection of his/her exterior. But what provides a reflection of the essential person - his/her thoughts, emotions, and perceptions? My answer has been that only another human being can provide that reflection. The process is known as active listening or empathic responding. Other responses from the therapist may serve as social reinforcers, and a lack of a response from the therapist may put the behavior that preceded it on extinction. Even Carl Rogers appeared to reinforce some client responses and extinguish others (Truax, 1966).

\section{Empirically Supported Therapeutic Treatments and Relationships}

The American Psychological Association’s (APA) Division of Clinical Psychology (Division 12) has invested much effort to identify empirically supported treatments (ESTs) (Chambless \& Hollon, 1998; Chambless et al., 1996). In contrast, APA’s Division of Psychotherapy (29) has argued for empirically supported therapy relationships (Norcross, 2001). In recent years I have attended many symposia that addressed and debated issues raised by these two efforts. Division 12 has been invested in identifying empirically supported or validated packages of components designed to treat a particular clinical entity, such as, alcoholism, attention-deficit/hyperactivity disorder, borderline personality disorder, conduct disorder, depression, eating disorders, enuresis and encopresis, generalized anxiety disorder, obesity, obsessive compulsive disorder, oppositional defiant disorder, panic disorder and agoraphobia, post-traumatic stress disorder, sexual dysfunctions, social phobia, and specific phobias. The empirically supported treatments are closely associated with treatment manuals that articulate each treatment package (e.g., Barlow, 1993; Klerman, Weissman, Rounsaville, \& Chevron, 1994; Mash \& Barkley, 1989). I have favored the development of such treatment packages throughout my career.

On the other hand, I have also always believed that additional ingredients contribute to successful psychotherapy. I agree with Norcross' (2001) summary of the Division 29 Task Force effort: "The dual aims of the Division 29 Task Force were to identify elements of effective therapy relationships and to determine efficacious methods of customizing or tailoring therapy to the individual patient" (p. 345). One of my intentions in writing the present article is to illustrate a combination of the recommendations of the Division 12 and 29 task forces.

\section{A Pragmatic, Problem-Solving Focus}

Before becoming a swimming instructor and lifeguard I had been a farm boy. Growing up on a small farm north of Seattle had biased me toward discovering practical solutions to everyday problems. In contrast, during my training years in psychology I was surprised by the emphasis on theories and theoretical debates. As a student I was interested in pragmatic approaches that described how to help. Similarly, I wanted to discover therapeutic approaches that had empirically demonstrated their helpfulness rather than those promoted by theoretical arguments instead of data to justify their use. Also, I desired to improve on previous treatment outcome studies and be able to demonstrate that psychotherapy can produce more change than no treatment. I wanted to help develop better treatment approaches and see other colleagues do likewise. 
During the four decades of my career countless people have asked, "What kind of a psychotherapist are you? Freudian? Rogerian? Skinnerian? Or what?” I have answered in various ways over the years, but my most common answer is that while I borrow a fair amount from the cognitive-behavioral tradition, among others, I am most of all a displaced Washington state farm boy. My primary biases have always been practical, pragmatic, and empirical. Competing theories of personality and psychotherapy were king during my training years, but I always found myself impatient with and irritated by theoretical debates. I was in search of finding better ways of helping people. I have been interested in identifying interventions that are likely to be helpful to a given person I have in treatment. Across my career I have learned from a very large number of researchers and practitioners. I am happy to beg, borrow, or steal methods from anyone regardless of their theoretical orientation and regardless of whether they are a laboratory researcher or real-world practitioner. At the same time I have always wanted to measure the effects of my efforts. I have been committed to measure my treatment outcomes.

\section{ASSESSMENT OF THE CLIENT'S PRESENTING PROBLEMS, HISTORY, GOALS, AND STRENTH}

\section{Presenting Problems}

As mentioned earlier, Hope was 30 years old at intake and sought treatment because, "I have always been a perfectionist. I 'tidy up.' If I don't tidy up, people will die. If I resist tidying up, I get so anxious that I can't focus.” Her particular motivation for seeking treatment seemed to be her husband's absence on a business trip, which stimulated recurring obsessions that tidying up would give protection against anything bad happening to him while he was traveling. On the other hand, she felt that if she didn't tidy up, he would probably die or be injured.

\section{History}

Hope grew up in a western European country as an only child. When she was $4 \frac{1}{2} \mathrm{her}$ father left the home, and her parents divorced when she was 5. From that time forward she was plagued by separation anxiety. She was 7 when her mother became involved with another man. Although her mother never married the man, he moved in with them when Hope was 9. From that time onward she perceived him as her step-father.

When her father left her mother, he left to be with another woman. They lived together for 10 years but never got married. Hope was 6 when she first met this woman and remembers that the woman was always nice to her but not to her father. She ordered him around a lot and eventually left him. About three years later her father did marry still another woman, and Hope served as a witness at the wedding.

Hope stated that her step-parents never played a very important role in her life. Her main thought was that her parents' relationships were all dysfunctional and that her biological parents chose partners that were not a great match. She said, "I just wish my parents had been happier with the people they decided to spend their lives with after getting divorced." (Note that in the 
Story of "Hope": Successful Treatment of Obsessive Compulsive Disorder

narrative below, reference to Hope’s “parents” refers to either her biological mother, her biological father, or both.)

She stated that she and her mother had very different personalities. Hope was a dreamer, and her mother was very practical. Hope was an only grandchild. Both her mother and her maternal grandparents were very protective of her. She had poor health as a child. Her maternal grandmother had many rules for her, such as, don’t sweat or you will get sick.

She reported that she loved her father but she had always been more of a mother to him than his daughter. In contrast, Hope's mother and maternal relatives saw her as a poor child who didn't have a father even though he lived in the same city. During her adult years both parents often complained to Hope about their partners.

As a child she was happy on the outside but anxious on the inside. She had horrible fears. For example, she believed that aliens were going to get her.

She entered preschool at age 4. Her maternal grandmother took her to and from preschool. She was always afraid that her grandmother would not pick her up. These fears got worse after her father left. She attended public schools in her city from kindergarten through high school. She had looked forward to learning to read in elementary school and became the fastest reader in her class, but she was never very good at math. She studied foreign languages in high school. Following high school she attended the major university in her city. She had wanted to pursue medicine following her undergraduate studies, but her mother discouraged her from doing so. Instead of pre-medicine she majored in political science, international law, and history plus she continued to study English and one other foreign language. She was fluent in five.

During her fourth year of college she went to study in England. That is where she met the man who would eventually become her husband. He was from a third European country, so their native tongues were different. She spoke his language so flawlessly, however, that natives of his homeland thought that she was one of them when they heard her speak. During the time that she was in treatment with me she was a Ph.D. candidate in a world-famous university in her husband's native country.

She married in the spring of 2000. During the intake interview she reported that she had not believed in marriage and did not want to marry. They lived together for $2 \frac{1}{2} 2$ years before marrying, and he proposed to her during the last 2 of them. He obtained a Ph.D. in one of the sciences from a European university. Then they came to the United States in order for him to pursue an academic career. At home they spoke his native tongue when they were alone.

Although living in a foreign country, she had developed a circle of friends that included at least 11 people. She did many activities with her friends including exercise classes, eating out, cooking together in someone's home, going to coffee shops, going to the movies, and hanging out at the beach. In spite of this full social life she said that she always felt like she needed more friends. She had chronic fears that people weren't going to like her, but the only complaint she could recall was that she didn't call them enough. Also, when she started dating her husband, the 
Story of "Hope": Successful Treatment of Obsessive Compulsive Disorder

friends from her own native country rejected her because of his nationality. In addition, he tended not to make friends, so all of their friends were her friends.

She grew up in the Roman Catholic tradition, and her husband in a protestant tradition. She stopped attending church at about age 12 or 13, but she did not emotionally leave her church until she moved to England at age 22. During childhood and early adolescence she remained quite active attending church school twice a week and mass once a week. She said that the Roman Catholic Church had given her a narrow perspective on life. She had moved on to a very personal kind of spirituality. She reported, “I am a seeker.” Neither she nor her husband was involved in a church or religious community during the course of her treatment.

She first learned about sex at age five when some workers answered her questions. More specifically at age 11 she learned from a friend how one gets pregnant. Her parents were very open about sex and made clear to her that they enjoyed the sexual part of their lives. Her first sexual intercourse was at age 17 with her boyfriend of the preceding year. They had talked about having sex before doing so. The only guilt she had experienced regarding sex was that she had a sexual relationship with a young man from her home city after she had been dating her husband but before they got married; however, the guilt feelings did not start until after she began obsessing about contracting HIV.

During her childhood and youth she had never been a victim of physical abuse, sexual abuse, or neglect.

The medical histories of her blood relatives included the following: Her paternal grandmother had breast cancer at age 48. Her maternal grandmother developed heart problems at the same age. A maternal uncle died of cancer of the pancreas and liver. The only relative reported to have had a psychiatric history was her paternal grandmother who had a "nervous breakdown” at age 38. She received "sleep therapy” for a week. Hope also reported that her parents had histories of "tidying up," but they had never been diagnosed or treated by a mental health professional. She identified only one relative as having had a problem with drugs or alcohol. Her mother's cousin was a drug addict and died of AIDS.

Hope appeared to be in good health at the time of intake. She had completed a physical exam just 10 days before our first appointment. She was medium size and weight. Her weight was relatively stable, but she tended to weigh less in the summer than during the rest of the year. Although she drank beer when she was younger, she did not drink as of the time she started seeing me. She usually had one cup of decaffeinated coffee a day. She smoked from age 19 to 22 but not any more. She did yoga four to five times a week for two and a half hours per occasion. She also did some hiking on the weekends.

Earlier in her life her primary care physician prescribed an anti-anxiety medication that she took for about one and a half years. When she stopped taking it, she felt dependent on it. While on the medication, she felt sleepy all of the time. One month before moving to the United States she saw a psychiatrist in daily psychotherapy. Upon arrival in California she saw a clinical psychologist for about one and a half years. Just before coming to see me she consulted a psychiatrist who gave her a prescription for Xanax, but she had not taken any. 
Story of "Hope": Successful Treatment of Obsessive Compulsive Disorder

\section{Treatment Goals}

Hope stated that her goals for treatment were to break the obsessive-compulsive cycle and to be able to understand that there is no connection between her compulsive actions and what happens to others. She wasn't sure how long treatment would take but guessed that it might take three or four months.

At intake Hope was given the Adult Problem Checklist (Clement, 1999). As shown in Appendix 1, on this instrument the client is presented with a list of items and asked to indicate the degree of concern (if any) that he/she has about the item, from "1-a persistent danger to self or others," to "8-slight concern.” Below are the eight items on which she indicate a rating of 1-6.

$\begin{array}{ll}\text { Anxious, Tense, Worried } & \text { “5-Serious Concern” } \\ \text { Bad Dreams or Nightmares } & \text { “6-Moderate Concern” } \\ \text { Bothered by Recurring Thoughts } & \text { “4-Major Concern” } \\ \text { Fears or Phobias (flying) } & \text { “5-Serious Concern” } \\ \text { Feeling Detached from Myself } & \text { “4-Major Concern” } \\ \text { Job/Work Performance } & \text { “5-Serious Concern” } \\ \text { Panic } & \text { “1-Inability to Function” } \\ \text { Performing Unusual Habits or Rituals } & \end{array}$

\section{Diagnosis}

Based on the preceding items, what she said in the intake interview, and her responses to the Adult Self-Report Inventory - 4 (Checkmate, 1999), my diagnostic impressions were as follows:

$\begin{array}{ll}\text { Axis I: } & 300.30 \text { Obsessive-Compulsive Disorder } \\ \text { Axis I: } & 300.29 \text { Specific Phobia (flying) } \\ \text { Axis I: } & 300.01 \text { Panic Disorder without Agoraphobia } \\ \text { Axis I: } & 307.47 \text { Nightmare Disorder } \\ \text { Axis II: } & \text { V71.09 (no diagnosis on Axis II) } \\ \text { Axis III: } & \text { none } \\ \text { Axis IV: } & \text { Economic stresses based on not having a Green Card } \\ \text { Axis Va: } & \text { GAF at intake }=40 \\ \text { Axis Vb: } & \text { Highest GAF in year before intake }=40\end{array}$

Hope had had a physical examination just 10 days before our initial session. The doctor did not find anything wrong with her physically. Her most recent blood test had been seven 
months earlier, and she had an EKG performed about five months prior to our first contact. Although she seemed physically healthy at intake, she had a medical history that included three kidney infections and many bladder infections since age 19.

\section{Strengths}

In contrast to her multiple presenting problems, Hope was an excellent example of the “yavis” syndrome. She was young, attractive, verbal (in five languages!), intelligent, and successful. Her intelligence was not limited to "book smarts.” Although I did not administer a formal measure, she clearly scored high on emotional intelligence (Goleman, 1995). She had a good sense of humor and was quick to get the point of jokes in English even though that was not her native language. She had many strengths we could exploit during the course of her therapy.

\section{FORMULATION AND TREATMENT PLAN}

\section{Case Formulation}

Many childhood events seemed to contribute to Hope's development of pervasive problems with anxiety. Her father's departure from the home and 6 months later her parents' divorced when she was 5 (a time that many child psychologists view as a critical stage of development) may have been the first sensitizing experiences. These events seemed to lead to the development of a Separation Anxiety Disorder. Poor health during childhood also probably raised her sense of vulnerability. Anxiety-provoking messages from her parents and grandparents, no doubt, added to her susceptibility to waves of anxiety. Apparently both of her parents modeled obsessive-compulsive behaviors during her growing years. She may well have also inherited from them a genetic propensity to become anxious easily. By her own description she kept her worries and anxieties to herself. This secrecy may also have helped to set her up for the development of obsessive-compulsive patterns.

When at age 30 she came to see me there were several factors maintaining high levels of anxiety. She was living in a foreign country thousands of miles from her family, relatives, and friends. Although she was fluent in English, prolonged speaking in English made her tired. In spite of having marketable skills she could not have a normal job; she did not have a Green Card and did not know when she would qualify for one. Various actions and decisions of the United States government following September 11, 2001 added to her experienced vulnerability. Telephone conversations with her parents tended to leave her more distressed rather than relieved, because they tended to lean on her emotionally rather than giving her support. At the beginning of treatment her husband was in a temporary position. He was looking for a permanent academic post in a major university. He was considering positions throughout the U.S., Canada, and certain European countries. She did not know where they would ultimately settle. This ambiguity about their future also elevated her anxiety. His frequent travels either triggered her separation anxiety when she didn't join him or her fear of flying when she did accompany him. As indicated earlier in presenting her history she engaged in much magical thinking that motivated many of her rituals. Finally, she had the pressures of writing her doctoral dissertation and preparing for her final oral defense. 
Although she perceived that she had benefited from her previous psychotherapy, at the time she came to see me she was experiencing much distress. She wanted to make some significant and long-term changes in the way she coped in her life.

\section{Treatment Plan}

Table 1 provides an overview of my treatment plan. This plan was not fully developed within the first few sessions. Part of it evolved over the course of treatment. Some goals such as "weaken the OCD pattern" were explicit. Other goals such as "increase self-acceptance” were implicit. Many of the treatment methods were based on a simple but old assumption; a very long time ago Guthrie (1938) articulated the basic formula for behavior change:

To break a habit it is first necessary to know the stimuli responsible for its release. It is then necessary to use whatever arts one has to cause the person to do something else in this situation. This is the full recipe. The situation will now itself lead to the substituted act. (pp. 386-387).

In the present instance the basic therapeutic strategy was to identify the circumstances under which problem thinking or action occurred and to replace it with adaptive, resilient, or successful cognitions or behaviors.

\section{COURSE OF THERAPY}

Because of the length of the therapy (103 sessions) and its pattern of interlocking and repeating themes, the summary of the therapy below is presented in terms of themes rather than in strictly chronological order.

\section{Initial Assessment}

The first phase of treatment included obtaining Hope's personal history, gathering other diagnostic information, determining her level of functioning at intake, setting goals for treatment, and forming a therapeutic alliance. I often explain to prospective and new patients that therapy has some similarities to dating. There is a factor of "chemistry." The fact that a close friend or family member has done well with one therapist does not guarantee that the new person and therapist will "click.” Fortunately, in the case of Hope I perceived early on that we had clicked.

\section{Weaken the OCD Pattern}

Obviously a core belief in OCD is that the patient must engage in her rituals. In Hope's case, she believed that, if she didn't engage in tidying up, something terrible would happen to her husband or to one of her family members in Europe. Rather than having her fight against her obsessions and compulsions, I asked her to pay attention to her obsessions and to the internal aspects of feeling compelled to carry out a ritual. To help both of us understand her more fully I asked her in the fourth session to keep a log or journal of her obsessions and compulsions. In that same session I explained the role of exposure and response prevention in the treatment of OCD (Riggs \& Foa, 1993). Her husband's frequent travels ensured us of opportunities for exposure. I proposed that rather than literally engaging in response prevention that she do two 
Story of "Hope": Successful Treatment of Obsessive Compulsive Disorder

things when faced with the urge to tidy up: (1) deliberately delay starting to tidy up, and (2) once you start tidying up, change some significant aspect (behavioral topography) of your tidying-up actions. For example, first, set a timer to go off in 15 minutes and don't start tidying up until the alarm goes off. Second, use your non-dominant hand to do the tidying up. We worked on these strategies during many of the early sessions plus in scattered sessions across the course of treatment including \#43, 50, 51, 75, 90, and 102.

During the first phase of treatment I also introduced the strategy of adopting an experimental or scientific approach to her problems. I told her that rather than asking why you get anxious and get caught up in OCD loops, explore how, when, and where you start obsessing and tidying up. Notice and accept your troubling thoughts as interesting but passing mental phenomena. Then begin playing or experimenting with them using the "delay" and "change topography” approaches.

Hope was very cooperative and compliant with my recommendations. As a result she made rapid progress.

\section{Increase Her Understanding}

Hope's second explicit goal for therapy was to increase her understanding that there is no connection between her rituals and what happens to others. I explained that the best way to reach this goal was to do real-world experiments as described in the preceding section. I often tell stories as a form of social modeling in my approach to therapy, so I told the following story to Hope.

There was a 14-year-old farm boy from a large family. One evening his most-loved uncle gave him and some of his brothers a lecture on the evils of masturbating. The uncle explained that, if they masturbated, they would lose their strength just like Samson did when his hair was cut off. That night the boy pondered what his uncle had said. After he got dressed the next morning he went out behind the barn where there was a large boulder. In his family a concrete sign of manhood was when you were big and strong enough to lift that boulder fully off of the ground. He squatted, grasped the boulder, and lifted it. After dropping the boulder back to the ground, he opened his fly, masturbated, buttoned back up, and conducted the post-test. He squatted one more time, clutched the boulder, and lifted it off the ground. His uncle had been wrong!

In the spirit of that story I encouraged Hope to put her dire predictions to experimental tests. After she conducted such experiments I also encouraged her to replace her dire predictions or irrational thoughts with realistic beliefs based on the results of her experiments. The essence of her experiments would be to do something other than her standard tidying up and then observe whether anyone she had worried about got sick, injured, or killed.

\section{Increase Calmness}

Although Hope had not explicitly asked me to help her increase her calmness, OCD is an anxiety disorder. Anxiety increases arousal and tension. Relaxation training is a tried and proven tool for lowering arousal and tension and promoting calmness. I suspected that increases in her anxiety could cue obsessing. Conversely, anything that could lower her anxiety could 
Story of "Hope": Successful Treatment of Obsessive Compulsive Disorder

decrease the probability that she would start obsessing. In light of these assumptions I did relaxation training with her during our third session, recorded the 25-minute session, and gave her the tape to play at home as a guide for practicing relaxation.

I gave her face-to-face Jacobsonian relaxation instructions (Jacobson, 1938) during an early session in my office. We covered the major muscle groups beginning with those of her hands and forearms and progressed through her body as follows: upper arms, forehead, eye lids, jaws, cheeks, tongue and upper throat, lips, neck, shoulders, back, chest, abdomen, buttocks, thighs, lower legs, and feet. With each group of muscles I asked her to tense the muscles and to release the tension as soon as I said, relax. I also instructed her to note the different sensations that occurred during tension and relaxation. Then I had her focus on what happens when she breathes in and out slowly. Next I asked her to hold her breath and to picture any remaining tensions being drawn to the center of her lungs and then released when I said the word, relax. Finally I led her through guided imagery focusing on calming scenes, such as, lying on her back in a mountain meadow, sitting on a log in a wooded area next to a flowing stream, and lying on top of her towel or blanket at an ocean beach listening to the waves rolling in and feeling the warmth of the sun on her skin.

In addition to promoting physiological calmness, I wanted to facilitate Hope's becoming more aware of her personal assets as a source of calmness and contentment. Following our twentieth session I gave Hope written instructions to go to www.authentichappiness.org. This is a consumer-oriented "positive psychology" website based on the work of Martin Seligman. The site introduces positive psychology as follows:

Positive Psychology ... [is] a new branch of psychology which focuses on the empirical study of such things as positive emotions, strengths-based character, and healthy institutions. His [Martin Seligman's] research has demonstrated that it is possible to be happier - to feel more satisfied, to be more engaged with life, find more meaning, have higher hopes, and probably even laugh and smile more, regardless of one's circumstances. Positive psychology interventions can also lastingly decrease depression symptoms.

In session 20 I asked her to take several of the measures that are available at no charge on that site. On the "Purpose in Life Questionnaire" scale the mean of her scores was the $10^{\text {th }}$ percentile. On the "General Happiness" scale she was at the $41^{\text {st }}$ percentile. Similarly, on the "Satisfaction with Life" scale she was at the $43^{\text {rd }}$ percentile. On the "Signature Strengths Survey” (Peterson \& Seligman, 2004), which measures 24 "character strengths,” Hope's top five values in descending rank order were "Capacity to Love and Be Loved" (94 ${ }^{\text {th }}$ percentile), “Appreciation of Beauty and Excellence” (89 $9^{\text {th }}$ percentile), "Gratitude” (85 $5^{\text {th }}$ percentile), "Fairness, Equity, and Justice” ( $78^{\text {th }}$ percentile), and "Kindness and Generosity” ( $70^{\text {th }}$ percentile).

One of the life strategies recommended by Seligman (2002) is to identify how to apply such character strengths to any problem being faced in the present. I encouraged Hope to apply her character strengths to any challenges that she was facing then or would be addressing in the future. I also shared with her several strategies that I learned from Martin Seligman from the fall of 2003 through the spring of 2004 in his course, “Authentic Happiness Coaching.” One of these 
was the “disputation exercise.” During session \#30, I gave Hope the following written instructions:

During the next week, before you go to bed, I want you to review one event that happened during the day. It can be good or bad, major or minor: The mail is late; your call isn't returned; you get complimented on your appearance; the kid pumping gas doesn't wash the windshield. Remember any pessimistic thought you actually had about the event, and then, in writing, dispute that thought vigorously. If you cannot remember a pessimistic thought about the event, make one up, and now dispute it vigorously.

The instructions included one example of a bad event and one of a good event presented in the ABCDE model: Adversity, Beliefs, Consequences (troubled feelings triggered by the beliefs), Disputation (the arguments against the troubling beliefs), and Energization (the emotions that follow the disputation of the troubling beliefs). In the following session Hope brought many pages of notes from her doing this therapy homework assignment. We spent this whole session reviewing and discussing her notes.

At the end of that session I gave her another written assignment drawn from Seligman's Authentic Happiness Coaching course:

Consider this quote by Winston Churchill: “A pessimist sees the difficulty in every opportunity; an optimist sees the opportunity in every difficulty." What does this quote mean to you? Do you tend to act like a pessimist or an optimist?

Optimism entails positive emotions about the future as well as present. The optimist thus sees the good in the bad, the silver lining, and the bright side. These views have become clichéd in the expression, but that does not diminish the validity of the optimist's perspective. Optimism does not make a person foolish or naïve. Indeed, optimism can be hard work, as this Doors Opening exercise suggests. Think of times when you lost out at something important, when a big plan collapsed, when you failed to get a job you wanted, when you were rejected by someone you loved. When one door closes, another one almost always opens. Consider three doors that closed on you. What doors opened?

Write about your experiences with doors opening and closing. Did you see the open door immediately, or did it take a while? Did your disappointment, sadness, or bitterness (or other negative feelings) resulting from the closed door affect your ability to find the open door? Are there things you can do in the future to find the open doors more readily?

In the subsequent session we processed her answers to these questions. I used many written assignments such as the preceding two during the course of our work together. This type of therapy homework is a common part of my approach to psychotherapy.

\section{Increase Resilience}

In spite of her many assets, Hope had lived much of her life thinking "nobody likes me." We explored the sources of this idea and contrasted it with the kind of social feedback she received from others. In general, I asked her to work on reducing the gap between her self- 
assessments and assessments of her by others. For example, although in many ways she described herself as a frightened little girl, I saw her as a "woman of the world" who grew up in one European country, studied in a second one, currently lived in a third (the United States), and was about to earn her Ph.D. from a fourth. From my point of view what she had already done in her life called for substantial resilience. Part of what I hoped that we would achieve in therapy was to tap into that resilience. Berg and Kim (1995) identified a very useful therapeutic strategy: Rather than trying to develop new coping skills, encourage the client to identify what has worked for them in the past and to employ those proficiencies in the present.

In many of our sessions I encouraged Hope to think out loud with me about her many capabilities and past successes. She went off to England on her own for her final year of college. She had the inner strength to choose her husband in spite of family and friends being opposed due to his nationality. She was fluent in five languages. She had moved across an ocean and a continent to southern California with her husband. She was seriously considering traveling on her own across the Pacific Ocean to an Asian country to study with an expert in her area of interest. She made friends easily wherever she found herself. She was bright. She was attractive. She had "book smarts" as well as showing considerable emotional intelligence. She liked helping other people. She was pursuing her Ph.D. from a famous European university, writing her dissertation in English, but doing her dissertation defense in another language that was not her native one. She had a vast range of assets to use in addressing any challenge in her life in the future.

In addition to encouraging Hope to tap into personal strengths, such as those listed above, during the middle of our therapeutic work (sessions \#53-59, 61, 71, and 72) we employed many exercises adapted from The Resilience Factor (Reivich \& Shatté, 2002).

The first exercise, "Learning Your ABCs," was very similar to the ABCDE assignment described earlier. The thrust of the charge was to identify negative or self-critical thoughts that are demoralizing. The main goal was to increase understanding of how thinking affects emotions and behavior.

The second exercise, “Avoiding Thinking Traps,” involved identifying the degree to which Hope made each of eight common thinking traps (jumping to conclusions, tunnel vision, magnifying and minimizing, personalizing, externalizing, over generalizing, mind reading, and emotional reasoning), and then ascertaining more resilient alternatives.

The third exercise, “Detecting Icebergs," asked her to specify her fundamental beliefs about what should and should not be and how such beliefs may cause her to overreact to certain situations.

The fourth exercise, "Challenging Beliefs," provided three pages of instructions for evaluating how she behaved the way she did when confronted by specific problems so that she could search for new approaches or solutions to those problems.

The fifth exercise, "Putting It in Perspective,” included three pages of instructions designed to encourage her to replace worries with focusing on solutions to real problems that 
exist in the present. During our sixtieth session Hope reported that many of the ideas we had worked on in therapy had come together inside of her. She felt like she had recovered her old self.

In the next session we covered the sixth resilience exercise, "Calming and Focusing," that asked her to use methods of relaxation when overwhelmed by emotion or stress so that she could focus on the immediate problem facing her.

Finally, in session \#72, I gave her the final resilience exercise, "Real-time Resilience,” giving her written instructions for changing counterproductive thoughts into more resilient ones with immediate results.

\section{Reduce Separation Anxiety}

Although Hope no longer met the criteria for Separation Anxiety Disorder that she did as a child, she was clear that periods of separation from her husband when he was away on business trips triggered obsessing, anxiety, and compulsive "tidying up." We specifically addressed her separation anxiety in sessions $2,5,7,8,23,24,49,58,60,67,75,89,96,101$, and 102 . We applied many of the methods described above to her separation anxiety. But we used others as well. For example, I asked her to use her favorite calming exercise from yoga when she began experiencing separation anxiety. She told me that standing on her head would do the trick!

\section{Cognitive Restructuring}

We examined the most common types of worry that triggered Hope's separation anxiety:

(1) What if ...?

(2) Predicting that a low-probability bad event is likely or certain.

(3) Thinking about a catastrophe.

Then I asked her to practice the "If __ then ___ formula: If [the bad thing happens], then I will [carry out a sensible action]. Similarly, when she became aware of a superstitious thought or of a type (2) or (3) worry (see above), I encouraged her to identify the realistic probability of the adversity.

\section{Reduce Frequency of Bad Dreams or Nightmares}

We did not specifically target bad dreams, but in our $26^{\text {th }}$ session I gave Hope therapeutic homework that could induce pleasant dreams. The gratitude assignment was adapted from Seligman (2002). Each day she was to identify three things for which she was thankful. At bed time she was to choose one of the three issues of gratitude, to identify anything she had done to help the good thing to have happened, and then to picture the good event as she was falling asleep.

I also encouraged her to play her relaxation tape at bed time, especially when her husband was away on a trip. 
Story of "Hope": Successful Treatment of Obsessive Compulsive Disorder

Submitted to: Pragmatic Case Studies in Psychotherapy, http://pcsp.libraries.rutgers. edu

Volume 3, Module 4, Article 1, pp. 1-36, 10-01-07 [copyright by author]

\section{Weaken Fear of Flying}

Although I have a long history of treating flying phobias with systematic desensitization and in vivo desensitization, I did not use these treatments with Hope. During the whole time that I was treating Hope, my wife and I were building an airplane in our garage. From time to time I talked to Hope about what we were doing as well as telling her anecdotes drawn from my experiences as a private pilot for over 35 years. The purpose of these stories was to serve as symbolic modeling.

We only spent four sessions $(11,15,77$, and 78$)$ focusing primarily on the fear of flying. I encouraged her to use relaxation as a coping tool. I also encouraged her to use any other positive behaviors that had worked in the past to lower her anxiety, such as, talking to other passengers, focusing on what she would do upon arrival at her destination, and remembering her successful coping with flights in her past.

\section{Increase Being Connected with Herself}

We did not do anything explicitly to increase Hope's experience of being connected with herself, but acceptance and empathic listening are two "common factors" of psychotherapy and they definitely were part of my contributions to the therapy process. My accepting her just as she was intended to serve as a social model for her to move toward greater self-acceptance. Secondly, as covered in the earlier section 3 on my Guiding Conception, I believe that active listening and feedback from the therapist can serve as a mirror to help the client see his/her essential self more accurately and fully. Hope was an impressive young woman, but when we started treatment she did not seem to have an accurate and comprehensive view of herself. Over time she clearly made progress toward this goal.

\section{Acceptance}

Another helpful strategy is to explore ways to apply the "serenity prayer": God, grant me serenity to accept the things I cannot change, courage to change the things I can, and wisdom to know the difference. Seligman (1993) provided extensive descriptions of what can be changed and what cannot be changed. A footnote to the title of his book reads, "learning to accept who you are.” Such self-acceptance is a central part of dialectical behavior therapy (e.g., Hayes, Follette, \& Linehan, 2004; Linehan, 1993a, 1993b; Marra, 2005). Just as acceptance by the therapist is an important precursor of change or growth, self-acceptance is an important antecedent of improvement.

\section{Improve Job or Work Performance}

Because Hope did not have a Green Card, she was unable to have normal employment during the time she was seeing me. Her situation was frustrating, as she had no idea of when she would be able to get a Green Card. We did discuss issues related to her deciding what to do with the rest of her life. Although she would be getting her Ph.D. soon, she had not decided whether to build her career on that degree. Part of our therapeutic work addressed her sense of purpose in life and her answer to the question, "Who needs you?" 
As mentioned earlier, during session 20 I asked Hope to take the "VIA Signature Strengths Survey" (Peterson \& Seligman, 2004). During sessions 21, 22, and 32 we discussed her results in order to help her to clarify her sense of purpose as a precursor to choosing a career path in which she would be productive and happy.

\section{Strengthening Self-soothing Methods When Facing Situations That Triggered Panic in the Past}

As with some other identified problems in her life, we did not explicitly target panic. Relaxation training, the Serenity Prayer, practicing various coping behaviors, and extensive cognitive restructuring probably all contributed to the fact that Hope did not suffer any panic attacks during the time that we worked together.

\section{Strengthening Skills to Cope with Medical and Dental Problems}

When Hope first came for treatment, she was not suffering from medical or dental problems; however, we wound up spending a substantial amount of therapy addressing such problems. She experienced substantial oral and abdominal pain. The cause of the abdominal pain was uncertain for some time, and she had a sharp rise in worries and anxiety. During this period of time she became obsessed with the belief that she had been infected with HIV.

We spent most of sessions 38, 40, 51, 64-72, 76-81, 86, 96, 97, and 100 addressing her medical and dental concerns. Similarly, we spent most of sessions 45-50, 80, 90, and 92 dealing with the HIV obsession.

Much of what I did was simply to listen to her as she described her experiences, diagnostic tests, diagnostic possibilities, and options for medical and dental treatment. In addition, I offered other input from time to time. For example, in session 40 I gave her a journal article that described differences in men and women as heroes. The stories about women often involved medical procedures such as donating one's own organs, like a kidney or bone marrow. My intention was that such stories could serve as symbolic modeling for her.

Given that her medical problems had triggered a recurrence of her OCD, I also asked her to use the disputation skills that she had previously learned to challenge her obsessions and to use delay and change tactics on her seeking reassurance (a type of compulsion) about being infected with HIV. The latter sessions that focused on obsessing about HIV and seeking reassurance that she had not been infected included "booster treatments" emphasizing reality testing, exposure, and response prevention. In addition, I had coached her to instruct her husband to ignore her attempts to get reassurance from him about HIV infection.

A powerful sign of her progress occurred in the week of our $92^{\text {nd }}$ session. She had been doing an internship at a nearby university. A fellow trainee had told her that he was HIV positive. Not surprisingly his confession triggered obsessing in her, but a few days before our session she had eaten a lunch prepared by this colleague. This event was a concrete example of exposure and response prevention. In the past she would have avoided such a lunch. 


\section{Empower Her to Deal with Her Parents}

From time to time throughout our working together Hope talked about how stressed she tended to become during and following telephone conversations with her parents. She first did so in the tenth session and returned to his area of difficulty in many additional sessions (13, 15 , $16,20,23-25,27,28,34,79-82,87$, and 98). During the first of these sessions she was preparing for a six-week visit to her home in Europe. An example of the kind of coaching that I sometimes do in therapy was to propose that she employ the proposition, "The best defense is no defense at all,” during her time with her parents and grandparents, i.e., just listening and not trying to defend against criticisms by them. In this same session she talked much about the propensity in her family for people to enjoy being sick and taken care of.

During her time in Europe she gave a talk that went well at the university where she was a Ph.D. candidate. During her time in her hometown she got to spend five hours with her great grandmother on the day that she died. Hope told me that she felt stronger as a result of having done so. Both of these experiences provided us concrete evidence of her competence. In contrast, during her lifetime her mother and maternal grandmother had often said things that undermined her sense of adequacy. I asked her to picture two groups of people and the things they tend to say about her: (1) her husband, me, and people like us, and (2) her mother, maternal grandmother, and people like them. Who is right? Which of these two groups has provided her with the most accurate feedback?

I also asked her to use strategies that she had learned in yoga to observe herself. My understanding was that such strategies were implicitly related to mindfulness and acceptance (Hayes, Follette, \& Linehan, 2004). Similarly, I prompted her to feel her anxiety or fear and then to pursue her positive goals anyway. One of her goals was to develop a better relationship with her mother who was visiting Hope at the time of our $27^{\text {th }}$ and $28^{\text {th }}$ sessions. I suggested that Hope propose to her mother that the two of them reframe their relationship as "friends." In general, on the various occasions that we discussed how she related to her parents, I encouraged her to be assertive, that is, to say what she felt, thought, perceived, wanted, or didn't want in a clear, calm, direct manner.

Hope's abdominal surgery happened between our $80^{\text {th }}$ and $81^{\text {st }}$ sessions. Her mother came from Europe to help out. After her mother had returned to her own home Hope told me in session \#82 that the two of them had had a good visit and did not fight. That did not mean that the two of them lived happily ever after. In session \#87 she talked about how frustrated she got when talking to either of her parents. Each complained of an unhappy marriage during most telephone conversations. Toward the end of treatment in session \#98 she expressed many troubled feelings about how her father had treated her during her life. I urged her to describe each critical incident involving her father and to tell him how she felt during each of them.

\section{Handling Uncertainties in Her Husband's Career}

My understanding is that ambiguity is a basic cause of anxiety. During most of the time that Hope was in treatment with me she was uncertain of where her husband's career would take them. At the very time that we were working to lower her anxieties the uncertainties of when and to where they would eventually be moving tended to raise her anxieties. These issues were a 
major focus of many sessions (\#12, 27-30, 33, 63, 77-79, 82, 85, 86, 94, 95, 97, and 100). My role in these discussions was mostly to listen with understanding to her thoughts, feelings, concerns, and preferences and to accept her as she was. From time to time I would also encourage her to be assertive in her conversations with her husband. Following the 2004 presidential election in the U.S., her husband announced that he did not want to stay in this country. He started looking for academic posts in Europe and Canada, but by our $86^{\text {th }}$ session he had accepted an academic appointment at a major research university in this country but far from southern California.

\section{Complete Ph.D. and Define Career Path}

Being a Ph.D. candidate at a university in Europe, not being able to work at a normal job in the U.S., and not being clear about what career path to follow were all reality-based problems in her life. We spent part of many sessions (\#15, 16, 20, 26, 32-34, 37,38, 54, 80, 84, 87-89, 96, and 102) dealing with these issues. As was true in my supporting her in dealing with uncertainties in her husband's career, my major role in these sessions that addressed her own career was to listen and to accept where she was at the time.

\section{Promote a Good Marriage}

Although I did not do any marital therapy with Hope and her husband, on many occasions (sessions \#62, 65, 71, 73, 76, 83, 92, and 97) her marriage and her relationship with her husband were her major concerns. As was true in tackling problems with her parents, what I mostly did during discussions about her marriage was to listen and accept with occasional encouragement to be assertive. Regarding the latter function, I did encourage her to tell her husband the kind of emotional support that she wanted from him, particularly when she was going through extensive diagnostic procedures and eventually through abdominal surgery. The stresses caused by her medical and dental problems as well as the associated pain seemed to strain her marital relationship. From her end of the relationship her tendency to obsess about possible HIV infection or cancer and her frequently seeking reassurance from him led her husband to become stressed and to accuse her of "always exaggerating."

The week before our $76^{\text {th }}$ session her aunt died of colon cancer in Europe. Their birthdays were just one day apart. The morning of our session Hope had met with her surgeon. Hope had previously learned that the abdominal pain she had been experiencing was from a mass in her abdomen. The doctor explained that the size of the mass in her abdomen had not changed in size, but the ultrasound revealed that the wall of the mass appeared to be thickening and that might be a sign of cancer. This medical news plus her aunt's death triggered much grief and anxiety. Furthermore, she was angry at her husband for what she perceived as his lack of response to her distress.

In our final session that addressed her marriage we reviewed "the game of chase." This is the phenomenon in which a boy chases a girl or a man chases a woman to their mutual delight. Part of what she was telling me was that her husband did not pursue her enough. I coached her in ways that she could give him guidance in the spirit of "let me help you help me!" 


\section{Stabilize Gains from Treatment and Prepare for Termination}

I believe that the long duration of our therapeutic work together helped to stabilize the gains that Hope made in the early phase. I suspect that if we had terminated after 20 sessions or so that she would have been likely to have lost some of her gains. As the preceding review of her treatment hopefully made clear, however, we tended to address most problems in her life many times during the course of therapy. There tended to be breaks in time between one or more sessions that focused on a particular problem. This pattern amounted to "spaced practice" or later occurrences served as booster treatments to earlier ones.

In our $93^{\text {rd }}$ session we began to discuss termination that we expected to take place in about four months. In this session Hope told me that at those times when she became clear that her own ideas -- rather than the reality of external situations -- was what was scaring her, the fears went away. This was an example of how she had absorbed a belief that was a central part of the cognitive behavioral therapy that we had been doing together. As she talked about her pending move I asked her what she wanted to give to her new city and what did she want to get from it.

In our final session I asked her for permission to write an article based on her treatment with me. I told her that I would like her to read the manuscript for accuracy and to make sure that her identity was adequately protected. We also agreed to stay in touch. In fact, she sent me a newsy email four months following our final session. About $8 \frac{1}{1} 2 \mathrm{months}$ after our final session we were able to meet for coffee in her new city, and she gave me an update on her life. Slightly more than 11 months following our last session I sent her the first draft of the present case study and asked her to re-evaluate herself on the Adult Problems Checklist (see Table 2). She responded promptly, and I made some revisions in the manuscript based on what she sent back. When the present paper is published, I intend to send a copy of it to Hope along with any published responses to this case presentation. I anticipate that these papers and our touching base from time to time will help Hope to maintain or even to increase her gain over time.

When we began working together, neither of us predicted that Hope's treatment would last more than two and a half years, but it had. We had formed a strong bond, and no longer meeting Friday afternoons at 2:00 was a loss. Her mother had asked her what Hope was going to do when she moved out of state and could no longer see Paul. I believed that her many personal skills and strengths would allow her to deal successfully with whatever challenges faced her after leaving California.

\section{THERAPY MONITORING AND USE OF FEEDBACK INFORMATION}

As mentioned earlier I gave therapeutic homework assignments during most sessions. An important part of therapy monitoring was to discuss the extent of compliance with each assignment and the impact on Hope from doing the assignment. As the preceding section describes, we addressed many issues in her life. I adjusted my input according to what she brought to therapy in a given session or chunk of time. 
Although I did get to meet her husband and also her mother during a visit to this country, I never conducted a conjoint treatment session and did not seek evaluative feedback from Hope's husband, mother, or anyone else other than Hope herself.

\section{CONCLUDING EVALUATION OF THE THERAPY'S PROCESS AND OUTCOME}

\section{Therapy Process}

When Hope first arrived at my office, she was ready to take action to change her OCD. We quickly formed a strong therapeutic alliance. She brought much to the therapeutic table. She was young, physically and socially attractive, highly verbal, intellectually and emotionally intelligent, and successful for a woman her age. For my part I was accepting, authentic, and empathic as well as often self-revealing. What I have mentioned so far in this paragraph might best be classified as "common factors" of psychotherapy.

There were many specific factors as well. They included adaptations of the use of research-based exposure and response strategies, Seligman's happiness-promoting exercises, and Reivich and Shatté's resilience-producing exercises.

In a fundamental sense Hope set the pace and the agenda for the flow of her therapy. Part of my approach was to focus on whatever was important to her at a given point in time. The farm boy in me intended to look for practical solutions to whatever she presented. I have a large number of specific methods or techniques from which I may select. My years of being a swimming instructor taught me to take each student where he or she was and then to help move them forward. That has been my same approach in therapy. In teaching swimming I would model a particular behavior; ask the student to do what I had modeled as I watched; ask the student to practice in my absence; and then we celebrated each success. Fundamentally that is what I do in therapy. I do modeling. Then I say, You do it! As my client reports successes between treatment sessions, we celebrate those successes together. That is often what happened in what Hope and I did together.

I performed many rescues as a lifeguard. Each rescue was unique. Yet I had learned a set of lifesaving techniques from which to choose for a particular rescue, although each rescue called for my applying and adapting a limited number of these techniques. Basically this was the same kind of process that I followed in working with Hope. In water rescues, the best rescue is one in which the victim rescues him/herself under the guidance of the lifeguard. In the present case I saw myself as Hope's lifeguard. I guided her safely through the heavy surf of her life to shore, but the fact was that she had rescued herself.

\section{Quantitative Outcome Evaluation}

A quantitative evaluation of treatment outcome is presented in Table 2. This table lists the eight items that Hope identified as problems (from the Adult Problem Checklist in Appendix 
1), which she rated on a "Scale of Functioning” (SOF; Clement 1999) just before our intake interview. She re-evaluated herself three additional times, during the $14^{\text {th }}, 69^{\text {th }}$, and final $103^{\text {rd }}$ sessions and at one-year follow-up. The SOF ratings range from " $10=$ Excellent Functioning" to "1 = In Persistent Danger of Hurting Self or Others" (see Table 2 for all the rating points on the scale). The mean and standard deviations of each of the SOF administrations is presented, along with the formula for the treatment "effect size" statistic that is calculated from these means and standard deviations.

The effect sizes at the bottom of Table 2 are very large and represent great improvement. For example, as mentioned earlier, the median of 28 effect sizes from cases of OCD treated in the past 14 years of my private practice is 1.30 and the mean is 1.65 . Hope's treatment effect size at termination was 3.95, indicating that she had a very positive outcome. Her results also compare very favorably with published reports of the results from RCTs with OCD. Specifically, van Blakom, van Oppen, Vermeulen, van Dyck, Nauta, \& Vorst (1994) performed a metaanalysis of 86 studies published between 1970 and 1993. These studies included 2,569 patients who completed treatment. Averaging across four types of treatment (behavior therapy, cognitive therapy, behavior therapy + placebo, and behavior therapy + cognitive therapy) the mean effect size based on self-ratings at the end of treatment was 1.38 and 1.56 when based on ratings from assessors. Ten years later Eddy et al. (2004) performed a meta-analysis on studies published between 1980 and 2001. Their review included 705 patients who averaged 16 sessions and 22 hours of treatment. The mean effect size was 1.12 with a median of 1.04. Hope's score of 3.95 was much larger than these results from approximately 30 years of RCTs with people suffering from OCD.

Eddy et al. (2004) did a supplemental analysis calculating treatment effect sizes within experimental conditions. The mean effect size for pre-to-post measures of treated subjects was $1.52(\mathrm{SD}=0.66$, median $=1.19)$. The corresponding mean of control subjects was $0.12(\mathrm{SD}=$ 0.21, median = 0.12). Although Eddy et al. did not report effect sizes for follow-up, van Balkom et al. (1994) did. Unfortunately, most studies did not include follow-up data. Those that did had follow-up periods of less than 6 months or between 6 to 12 months. Based on self-ratings the mean effect size for these shorter follow-up periods was $1.34(\mathrm{SD}=0.36)$ and $1.66(\mathrm{SD}=0.56)$ based on assessor ratings. Only one reviewed study had a follow-up period of one year or more; it only had data based on self-ratings producing an effect size of 0.66 . Hope's one-year followup score of 3.81 was stunningly larger than these preceding results. Also important to note is the fact that Hope maintained her post-treatment gains during a one-year follow-up.

As seen in Table 2, Hope showed a decrease in her improvement from session 14 to session 69, with a drop in effect size from 2.59 to 1.91. This drop occurred when Hope was in the midst of her medical problems, and reflects the increase in her distress and dysfunction that I noted clinically. If she had not faced significant health issues and physical pain, I believe that the treatment effect size at session 69 would have fallen somewhere between those at sessions 14 and 103. Approximately one year after termination Hope again evaluated her level of functioning. The results appear in the final column of Table 2. She maintained her over-all level of improvement achieved at the end of treatment, but her evaluation of how she was doing with "performing unusual habits or rituals" suggests that she will face some long-term challenges in managing her propensity to engage in rituals. 
Story of "Hope": Successful Treatment of Obsessive Compulsive Disorder

Submitted to: Pragmatic Case Studies in Psychotherapy, http://pcsp.libraries.rutgers.edu

Volume 3, Module 4, Article 1, pp. 1-36, 10-01-07 [copyright by author]

\section{Follow-Up Contacts}

Four months following our final session Hope sent me an e-mail. The following statements were included in her news:

[My husband] and I are doing well. We have been enjoying [our new city] a lot and have been quite happy here so far.

We went through our green card medical examination deal all right ... meaning that neither [my husband] or myself tested positive for the group of diseases that they were testing us for ... not even HIV ... who would have thought? Not me for sure. As you can imagine, it was quite hard for me to get tested for HIV again but I kept thinking of what you used to tell me....

Also, since the move [my husband] has already gone on one of his business trips and has left me all alone ... and I think I managed quite well. I was very proud of myself.

I miss you Paul but I think that I miss you in a good way. Like you will miss a good, old friend that you trust deeply and you can always rely on when you have lost faith in yourself.

I will never thank you enough for having shown me my true potential and for having planted so many useful advices in my little head.

Four months after I received the preceding message my wife and I met with Hope for coffee. (My approach to the therapeutic relationship as a "real" person is reflected in this type of meeting after therapy.) We were on our way to the 2006 annual meeting of the American Psychological Association. She gave us an update. Shortly after she had sent me her e-mail she flew by herself and relatively comfortably from the U.S. to Canada and from Canada to Europe to sit for her dissertation defense. She had passed with honors. She had also traveled on her own to her home country to visit her parents, other relatives, and friends and to renew her visa. Following her visit she flew back on her own to the U.S. and was pleased with the way that she had handled these extensive travels between continents. She was doing an internship in a local nonprofit organization and seemed happy, relaxed, and confident.

Finally, I had some contact with Hope at a 21-month, post-treatment follow-up. During this time I readministered the 1-10 Scale of Functioning on the eight problem items listed in Table 2. On this measure, Hope showed some drop in her level of functioning, although her treatment effect size was still very large (2.57). For qualitative details and discussion of this follow-up contact, see the final, Epilogue section (Clement, 2007, pp. 66-68) of my response to the commentaries in this PCSP journal about Hope's case.

\section{REFERENCES}

APA Presidential Task Force (2006). Evidence based practice in psychology. American Psychologist, 61, 271-285.

Barlow, D.H. (1993). Clinical Handbook of psychological disorders: A step-by-step treatment manual $\left(2^{\text {nd }} e d\right)$. New York: Guilford Press. 
Story of "Hope": Successful Treatment of Obsessive Compulsive Disorder

Submitted to: Pragmatic Case Studies in Psychotherapy, http://pcsp.libraries.rutgers.edu

Volume 3, Module 4, Article 1, pp. 1-36, 10-01-07 [copyright by author]

Chambless, D.L., \& Hollon, S.D. (1998). Defining empirically supported therapies. Journal of Consulting and Clinical Psychology, 64, 497-504.

Chambless, D.L., Sanderson, W.C., Shoham, V., Bennet Johnson, S., Pope, K.S., CritsChristoph, P., et al. (1996). An update on empirically validated therapies. The Clinical Psychologist, 49(2), 5-14.

Checkmate Plus. (1999). Adult Self-Report Inventory-4. Stony Brook, N.Y.: The author.

Clement, P. W. (1968). Operant conditioning in group psychotherapy with children. Journal of School Health, 38, 271-278.

Clement, P. W. (1980). A system for describing therapeutic interventions. Pasadena, CA: Graduate School of Psychology, Fuller Theological Seminary. (ERIC Document Reproduction Service No. ED 013 371).Clement, P. W. (1990, April 26). Functional organization of clinical materials in a client's case folder. Western Psychological Association Annual Convention, Los Angeles.

Clement, P. W. (1992, May 2). Merging pre-treatment assessment, goals/objectives, and evaluation of post-treatment outcome. Western Psychological Association Convention, Portland, OR.

Clement, P.W. (1994). Quantitative evaluation of 26 years of private practice. Professional Psychology: Research and Practice, 25(2), 173-176.

Clement, P. W. (1996). Evaluation in private practice. Clinical Psychology: Science and Practice, 3, 146-159.

Clement, P. W. (1999). Outcomes and incomes: How to evaluate, improve, and market your psychotherapy practice by measuring outcomes. New York: Guilford Press.

Clement, P.W. (2007). Story of "Hope:" Successful treatment of obsessive-compulsive disorder. ” Pragmatic Case Studies in Psychotherapy [Online], Vol. 3(4), Article 1, 1-36. Available: http://hdl.rutgers.edu/1782.1/pcsp_journal

Clement, P. W., Anderson, E. E., Arnold, J. R., Butman, R., E., Fantuzzo, J. W., \& Low, B. (1982). Self-observation and self-reinforcement by socially deviant children. Behavioral Counseling Quarterly, 2, 168-182.

Clement, P. W., Fazzone, R. A., \& Goldstein, B. (1970). Tangible reinforcers and child group therapy. Journal of the American Academy of Child Psychiatry, 9, 409-427.

Clement, P. W., \& Milne, D. C. (1967). Group play therapy and tangible reinforcers used to modify the behavior of eight-year-old boys. Behaviour Research and Therapy, 5, 301312.

Clement, P. W., Roberts, P. W., \& Lantz, C. E. (1970). Social models and token reinforcement in the treatment of shy, withdrawn boys. Proceedings of the $78^{\text {th }}$ Annual Convention of the American Psychological Association, 5, 515-516.=

Eddy, K.T., Dutra, L., Bradley, R., \& Westen, D. (2004). A multidimensional meta-analysis of psychotherapy and pharmacotherapy for obsessive-compulsive disorder. Clinical Psychology Review, 24, 1011-1030.

Eysenck, H.J. (1952). The effects of psychotherapy: An evaluation. Journal of Consulting Psychology, 16, 319-324.

Eysenck, J.J. (1966). The effects of psychotherapy. New York: The International Science Press.

Foa, E.B., \& Wilson, E. (2001). Stop obsessing! How to overcome your obsessions and compulsions (Rev. Ed.). New York: Bantam Books.

Goleman, D. (1995). Emotional intelligence. New York: Bantam Books. 
Story of "Hope": Successful Treatment of Obsessive Compulsive Disorder

P.W. Clement

Submitted to: Pragmatic Case Studies in Psychotherapy, http://pcsp.libraries.rutgers.edu

Volume 3, Module 4, Article 1, pp. 1-36, 10-01-07 [copyright by author]

Guthrie, E. R. (1938). The psychology of human conflict: The clash of motives within the individual. New York: Harper \& Brothers.

Hayes, S.C., Follette, V.M., \& Linehan, M.M. (eds.) (2004). Mindfulness and acceptance: Expanding the cognitive-behavioral tradition. New York: Guilford Press.

Howard, K. L., Kopta, S. M., Krause, M. S., \& Orlinsky, D. E. (1986). The dose-effect relationship in psychotherapy. American Psychologist, 41, 159-164.

Jacobson, E. (1938). Progressive relaxation. Chicago: University of Chicago Press.

Klerman, G.L., Weissman, M.M., Rounsaville, B.J., \& Chevron, E.S. (1994). Interpersonal psychotherapy of depression. Northvale, NJ: Jason Aronson.

Kopta, S., Howard, K, Lowry, J., \& Beutler, L. (1994). Patterns of symptomatic recovery in psychotherapy. Journal of Consulting and Clinical Psychology, 62, 1009-1016.

Levitt, E.E. (1957). The results of psychotherapy with children: An evaluation. Journal of Consulting Psychology, 21, 189-196.

Levitt, E.E. (1963). Psychotherapy with children: A further evaluation. Behaviour Research and Therapy, 1, 45-51.

Linehan, M.M. (1993a). Cognitive-behavioral therapy for borderline personality disorder. New York: Guilford Press.

Linehan, M.M. (1993b). Skills training manual for treating borderline personality disorder. New York: Guilford Press.

Marra, T. (2005). Dialectical behavioral therapy in private practice: A practical \& comprehensive guide. Oakland, CA: New Harbinger Publications.

Mash, E.J., \& Barkley, R.A. (1989). Treatment of childhood disorders. New York: Guilford Press.

Miller, S.D., \& Berg, I.K. (1995). The miracle method: A radically new approach to problem drinking. New York: W.W. Norton \& Co.

Norcross, J.C. (2001). Purposes, processes and products of the task force on empirically supported therapy relationships. Psychotherapy: Theory, Research, Practice, Training, 38, 345-356.

Peterson, C., \& Seligman, M.E.P. (2004). Character strengths and virtues: A handbook and classification. Washington, D.C.: American Psychological Association.

Prochaska, J.O., DiClemente, C.C., \& Norcross, J.C. (1992). In search of how people change: Applications to addictive behaviors. American Psychologist, 47, 1102-1114.

Reivich, K., \& Shatté, A. (2002). The resilience factor: 7 essential skills for overcoming life's inevitable obstacles. New York: Random House.

Riggs, D. S., \& Foa, E. (1993). Obsessive-compulsive disorder. In: D. Barlow (Ed.), Clinical handbook of psychological disorders: A step-by-step treatment manual (2 ${ }^{\text {nd }}$ ed.), 189239. New York: Guilford.

Rogers, C.R. (1957). The necessary and sufficient conditions of therapeutic personality change. Journal of Consulting Psychology, 21, 95-103.

Rosenzweig, S. (1936). Some implicit common factors in diverse methods of psychotherapy. American Journal of Orthopsychiatry, 6, 412-415 [reproduced in Journal of Psychotherapy Integration, 2002, 12, 5-9].

Seligman, M.E.P. (1993). What you can change ... and what you can't: The complete guide to successful self-improvement. New York: Fawcett Books.

Seligman, M.E.P. (1995). The effectiveness of psychotherapy. American Psychologist, 50, 965-974. 
Seligman, M.E.P. (2002). Authentic happiness: Using the new positive psychology to realize your potential for lasting fulfillment. New York: Free Press.

Smith, M.L., \& Glass, G.V. (1977). Meta-analysis of psychotherapy outcome studies. American Psychologist, 32, 752-760.

Smith, M.L., Glass, G.V., \& Miller, T.I. (1980). The benefits of psychotherapy. Baltimore: The Johns Hopkins University Press.

Truax, C. B. (1966). Reinforcement and nonreinforcement in Rogerian psychotherapy. Journal of Abnormal Psychology, 71, 1-9.

van Blakom, A.J.L.M., van Oppen, P., Vermeulen, A.W.A., van Dyck, R., Nauta, M.C.E., \& Vorst, H.C.M. (1994). A meta-analysis on the treatment of obsessive compulsive disorder: A comparison of antidepressants, behavior, and cognitive therapy. Clinical Psychology Review, 14, 359-381.

Westen, D., Novotny, C. M., \& Thompson-Brenner, H. (2004). The empirical status of empirically supported psychotherapies: Assumptions, findings, and reporting in controlled clinical trials. Psychological Bulletin, 130, 631-663.

Wolpe, J. (1961). The systematic desensitization treatment of neuroses. Journal of Nervous and Mental Disease, 132, 189-203. 
Table 1: Summary of the Treatment Plan for Hope

\begin{tabular}{|c|c|}
\hline Goal & Method(s) for Pursuing Goal \\
\hline Weaken the OCD pattern & $\begin{array}{l}\text { Exposure and response prevention } \\
\text { Delay doing the ritual \& change its topography } \\
\text { Acceptance and mindfulness } \\
\text { Real-world experiments } \\
\text { Cognitive restructuring }\end{array}$ \\
\hline $\begin{array}{l}\text { Increase her understanding that there is no } \\
\text { connection between her rituals and what } \\
\text { happens to others }\end{array}$ & $\begin{array}{l}\text { Conduct real-world experiments to test your } \\
\text { dire predictions } \\
\text { Cognitive restructuring }\end{array}$ \\
\hline Increase calmness & $\begin{array}{l}\text { Relaxation training } \\
\text { Authentic happiness training }\end{array}$ \\
\hline $\begin{array}{l}\text { Replace worries and disturbing thoughts with } \\
\text { more resilient cognitions }\end{array}$ & Resilience training \\
\hline Reduce separation anxiety & $\begin{array}{l}\text { Practicing positive behaviors } \\
\text { Cognitive restructuring } \\
\text { Mindfulness and self-acceptance } \\
\end{array}$ \\
\hline Reduce frequency of bad dreams or nightmares & $\begin{array}{l}\text { Relaxation } \\
\text { Gratitude exercise }\end{array}$ \\
\hline $\begin{array}{l}\text { Weaken fear of flying; strengthen strategies for } \\
\text { coping with flying }\end{array}$ & $\begin{array}{l}\text { Relaxation } \\
\text { Symbolic modeling } \\
\text { Practicing positive behaviors }\end{array}$ \\
\hline $\begin{array}{l}\text { Increase experience of being connected with } \\
\text { herself \& self-acceptance }\end{array}$ & $\begin{array}{l}\text { Acceptance } \\
\text { Active listening (empathy) }\end{array}$ \\
\hline Improve job or work performance & Clarify purpose in life \\
\hline $\begin{array}{l}\text { Strengthen self-soothing methods when facing } \\
\text { situations that triggered panic in the past }\end{array}$ & $\begin{array}{l}\text { Relaxation } \\
\text { Serenity Prayer } \\
\text { Practicing positive behaviors }\end{array}$ \\
\hline $\begin{array}{l}\text { Strengthen skills to cope with medical and } \\
\text { dental problems }\end{array}$ & $\begin{array}{l}\text { Acceptance } \\
\text { Active listening (empathy) } \\
\text { Symbolic modeling }\end{array}$ \\
\hline $\begin{array}{l}\text { Empower her to deal with her parents and } \\
\text { relatives in Europe }\end{array}$ & $\begin{array}{l}\text { Acceptance } \\
\text { Active listening (empathy) } \\
\text { Assertiveness training }\end{array}$ \\
\hline $\begin{array}{l}\text { Fortify her handling uncertainties in her } \\
\text { husband's career and possible job locations }\end{array}$ & $\begin{array}{l}\text { Acceptance } \\
\text { Active listening (empathy) }\end{array}$ \\
\hline $\begin{array}{l}\text { Enhance her preparations to complete her } \\
\text { Ph.D. and to define her career path }\end{array}$ & $\begin{array}{l}\text { Acceptance } \\
\text { Active listening (empathy) }\end{array}$ \\
\hline $\begin{array}{l}\text { Promote a good marriage and relationship with } \\
\text { her husband }\end{array}$ & Assertiveness training \\
\hline $\begin{array}{l}\text { Stabilize/maintain her gains from treatment } \\
\text { including preparing for termination }\end{array}$ & $\begin{array}{l}\text { Review previously helpful methods } \\
\text { Maintain post-treatment contact } \\
\text { Cognitive restructuring }\end{array}$ \\
\hline
\end{tabular}


$\underline{\text { Table 2: Hope’s Treatment Outcomes }}$

\begin{tabular}{|l|c|c|c|c|c|}
\hline \multicolumn{1}{|c|}{ Problem } & $\begin{array}{c}\text { SOF }^{\mathbf{a}} \\
\text { at } \\
\text { Intake }\end{array}$ & $\begin{array}{c}\text { SOF } \\
\text { at Session } \\
\mathbf{1 4}\end{array}$ & $\begin{array}{c}\text { SOF } \\
\text { at Session } \\
\mathbf{6 9}\end{array}$ & $\begin{array}{c}\text { SOF } \\
\text { at Session } \\
\mathbf{1 0 3} \\
\text { (termination) }\end{array}$ & $\begin{array}{c}\text { SOF } \\
\text { at One- } \\
\text { year } \\
\text { Follow-up }\end{array}$ \\
\hline Anxious, Tense, Worried & 5 & 6 & 7 & 8 & 8 \\
\hline Bad Dreams of Nightmares & 6 & 8 & 6 & 8 & 9 \\
\hline Bothered by Recurring Thoughts & 4 & 6.5 & 6 & 7 & 8 \\
\hline Fears or Phobias (flying) & 5 & 6.5 & 5 & 8 & 8 \\
\hline Feeling Detached from Myself & 5 & 8 & 6 & 9 & 9 \\
\hline Job/Work Performance & 4 & 8 & 7 & 9 & 8 \\
\hline Panic & 5 & 7 & 7 & 8 & 8 \\
\hline Performing Unusual Habits or Rituals & 3 & 6 & 7 & 9 & 7 \\
\hline Mean SOF Score $=$ & 4.62 & 7.00 & 6.38 & 8.25 & 8.12 \\
\hline Standard Deviation $=$ & 0.92 & 0.89 & 0.74 & 0.71 & 0.64 \\
\hline Treatment Effect Size (ES) & & 2.59 & 1.91 & 3.95 & 3.81 \\
\hline
\end{tabular}

${ }^{a}$ Scale of Functioning (SOF) Rating, on the following scale:

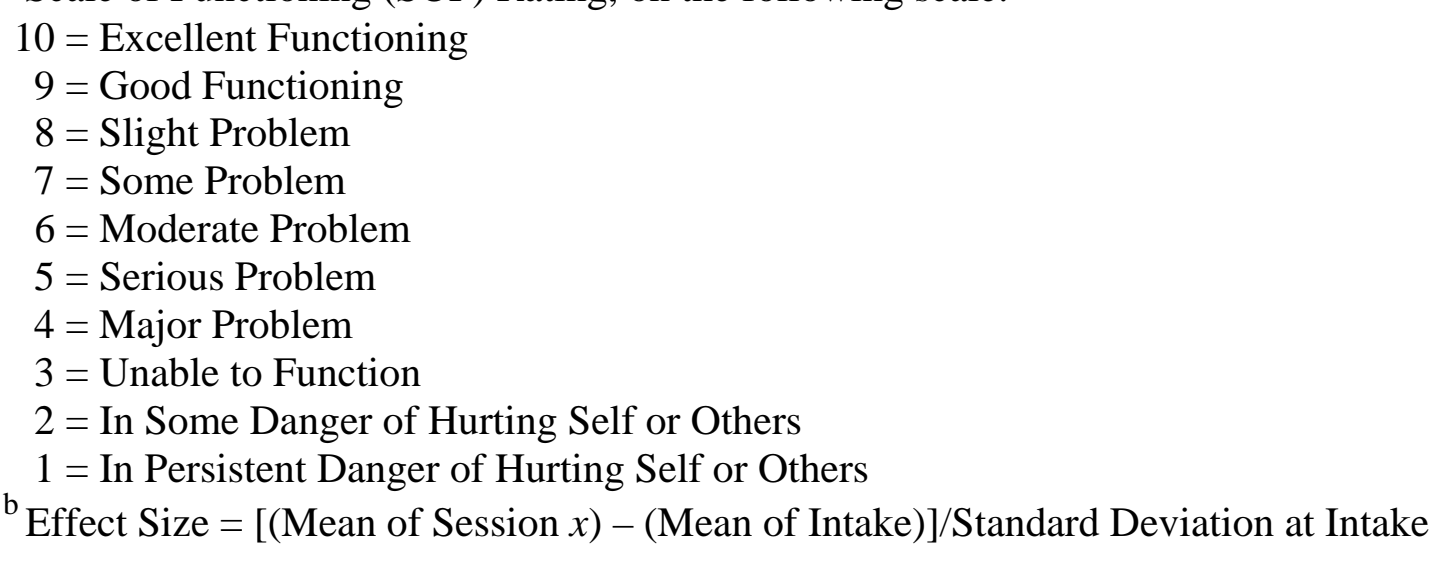


Submitted to: Pragmatic Case Studies in Psychotherapy, http://pcsp.libraries.rutgers. edu

Volume 3, Module 4, Article 1, pp. 1-36, 10-01-07 [copyright by author]

\section{Appendix 1: Adult Problems Checklist*}

Adult's Name:

Date:

Person completing this form:

Please identify your concerns about this adult by placing a number beside a problem, using the choices below. Do not place numbers next to problems about which you have no concerns.

$\mathbf{8}$ = Slight concern but I have not thought about getting help for this problem

$7=$ Some concern or I have thought about getting help for this problem

$\mathbf{6}=$ Moderate concern or someone has encouraged me to get help for this problem

$\mathbf{5}=$ Serious concern or a few people have encouraged me to get help for this problem

$4=$ Major concern or many people have pressured me to get help for this problem

$\mathbf{3}=$ Unable to function or I am totally unable to do what is age-appropriate in this area

$2=$ A danger to self or others some of the time

$1=$ A persistent danger to self or others

Acts without Thinking (Hyperactive or Impulsive)

Aggressive Behavior

Alcohol Consumption

Anger

Anxious, Tense, Worried

Appetite

Arguing

Bad Dreams or Nightmares

Being Ignored or Abandoned

Bothered by Recurring Thoughts

Bothered by a Traumatic Event

Bullying or Threatening Others

Career

Confused

Critical of Self

Destruction of Property

Eating

Energy Level

Family

Fears or Phobias

Feeling Detached from Myself

Fidgeting, Squirming, "Hyper"

Fighting

Finances

Grief, Bereavement

Guilt or Shame

Health Problems

Illegal Drugs or Substances

Illegal or Unlawful Behavior

Impact of Adult's Problems on Spouse

Impact of Adult's Problems on the Children Irritable
Legal Problems

Lonely

Lying

Making or Keeping Friends

Marriage

Memory

Mood Swings

Pain

Panic

Parent-Child Relationship

Paying Attention or Concentrating

Perfectionistic

Performing Unusual Habits or Rituals

Planning or Organizing Work

Procrastination

Restless

Sadness/Depression

Satisfaction with Life

Seeing or Hearing Strange Things

Self-Injurious Behavior or Suicide

Sexual Behavior or Responses

Shy

Sleeping

Social Skills

Social Support (Family and Friends)

Stealing

Strange, Weird, or Peculiar Behavior

Suspicious or Mistrustful

Thinking about Suicide

Trusting Other People

Using Nonprescription Drugs or Substances

Weight 
Submitted to: Pragmatic Case Studies in Psychotherapy, http://pcsp.libraries.rutgers.edu

Volume 3, Module 4, Article 1, pp. 1-36, 10-01-07 [copyright by author]

\section{Appendix 1: Adult Problems Checklist (cont.)}

Job/Work Attendance Job/Work Performance Job/Work Satisfaction Lack of Interest/Enjoyment in Life
Well-Being

Other:

Other:

Other:

*FORM 6.1. Adult Problems Checklist. From Outcomes and Incomes by Paul W. Clement. Copyright 1999 by The Guilford Press. Permission to photocopy this form is granted to purchasers of Outcomes and Incomes for personal use only (see copyright page of book for details). 